\title{
Access to New Medications for Hepatitis C for Medicaid Members: A Retrospective Cohort Study
}

\author{
Karen M. Clements, ScD, MPH; Robin E. Clark, PhD; Pavel Lavitas, PharmD, BCPS: \\ Parag Kunte, MPH; Camilla S. Graham, MD, MPH; Elizabeth O'Connell, MS; \\ Kimberly Lenz, PharmD; and Paul Jeffrey, PharmD
}

\begin{abstract}
BACKGROUND: Sofosbuvir (SOF)- or simeprevir (SIM)-containing regimens are highly effective for treating chronic hepatitis C virus (HCV) infection. These regimens, however, are expensive. Most payers have implemented prior authorization (PA) requirements to ensure that patients who can benefit most have priority for these medications. While many Medicaid programs limit access to those with advanced disease or to members who do not have active substance use disorder (SUD), the Massachusetts Medicaid (MassHealth) Primary Care Clinician (PCC) plan does not limit access based on disease severity or presence of SUD. Evaluating PA requests for SOF and/or SIM among MassHealth members will offer a useful example of early uptake among Medicaid members and will identify patient groups who might face barriers to treatment at the provider or patient level.
\end{abstract}

OBJECTIVES: To (a) evaluate the percentage of MassHealth PCC members with HCV who had a PA request, along with the percentage of requests approved, and (b) identify characteristics associated with PA requests for SOF or SIM among Massachusetts Medicaid (MassHealth) members with HCV.

METHODS: This retrospective cohort study used enrollment, medical claims, and PA request data from MassHealth PCC members from December 6, 2012, to July 31, 2014. The sample included members with 1 or more claims with an ICD-9-CM code for HCV during this time who were continuously enrolled from December 6, 2013, to July 31, 2014. Enrollment and medical claims data for the cohort with HCV were linked to a database containing information collected from PA requests. The overall percentage of members with HCV and a PA request for SOF and/or SIM between December 6, 2013, and July 31, 2014, and the percentage of requests approved were calculated. Chi-square statistics were used to compare demographic and clinical characteristics among members with HCV who did and did not have a request. Logistic regression was used to estimate the strength of associations between patient characteristics and a PA treatment request, adjusting for clinical and demographic variables.

RESULTS: Of 6,849 members identified with HCV, 346 (5.1\%) had a PA request for SOF and/or SIM submitted to MassHealth. Compared with members with HCV who did not have a PA request for SOF or SIM, those with a PA request for these new treatments were more likely to be male $(P=0.01)$, older $(P<0.001)$, white race $(P=0.04)$, have standard MassHealth insurance $(P=0.01)$, and less likely to be homeless $(P<0.001)$. Members with a PA request were also more likely to have been treated for HCV in the past year and have advanced disease (hepatic decompensation, cirrhosis, or liver transplant) but less likely to have SUD $(P<0.001$ for each). Ninety percent of requests for SOF or SIM were approved; few demographic or clinical characteristics were associated with approval. In adjusted analyses, predictors of PA request were aged 50-64 years (odds ratio $(0 R)=2.0$, $95 \% \mathrm{Cl}=1.1-3.7$ vs. aged $<30$ years); hepatic decompensation $(\mathrm{OR}=1.6$, $95 \% \mathrm{Cl}=1.2-2.3)$; cirrhosis $(\mathrm{OR}=3.0,95 \% \mathrm{Cl}=2.2-4.1)$; liver transplant $(0 \mathrm{R}=3.0,95 \% \mathrm{Cl}=1.4-6.5)$; substance use $(0 \mathrm{R}=0.6,95 \% \mathrm{Cl}=0.5-0.8)$; recent $\mathrm{HCV}$ treatment $(\mathrm{OR}=1.6,95 \% \mathrm{Cl}=1.0-2.6)$; comorbidity $(\mathrm{OR}=0.95$, $95 \% \mathrm{Cl}=0.91-0.98)$ for 1-unit increase in Diagnostic Cost Group score; and care at a hospital outpatient department $(\mathrm{OR}=2.0,95 \% \mathrm{Cl}=1.2-3.2$ vs. group practice).
CONCLUSIONS: Antiviral treatment with SOF and/or SIM was requested for a relatively small proportion of MassHealth members with HCV, with nearly all approved. Prescriber prioritization or patient barriers to care, rather than the PA process, determined access to treatment in this Medicaid population. Support may be needed to ensure patients with SUD benefit from advances in HCV treatment.

J Manag Care Spec Pharm. 2016;22(6):714-22

Copyright $\odot 2016$, Academy of Managed Care Pharmacy. All rights reserved.

\section{What is already known about this subject}

New medications for hepatitis $C$ have improved effectiveness but are expensive compared with traditional therapies.

With limited budgets, nearly all state Medicaid programs have implemented prior authorization (PA) requirements to manage access to newer medications to promote cost-effective use of resources.

Massachusetts Medicaid (MassHealth) has relatively few restrictions on hepatitis $\mathrm{C}$ virus (HCV) medications.

\section{What this study adds}

This study evaluated PA requests for treatment with sofosbuvir (SOF)- and simeprevir (SIM)-based regimens among MassHealth members with HCV and identified demographic, clinical, and provider-level characteristics associated with treatment request. Although few restrictions on access to SOF or SIM were imposed through the PA process, a low percentage of patients had a treatment request.

Several demographic and clinical characteristics were associated with having a PA request among HCV patients, suggesting provider prioritization and potential barriers to care. 
treatment required a course of treatment of up to 48 weeks, caused adverse events in a significant proportion of patients, and demonstrated an efficacy of only $63 \%-88 \% .^{5-7}$

Two much-anticipated medications, simeprevir (SIM; Olysio) and sofosbuvir (SOF; Sovaldi), were approved by the U.S. Food and Drug Administration (FDA) on November 22, 2013, and December 6, 2013, respectively. ${ }^{8,9}$ In combination with interferon and/or ribavirin or together as an all-oral dual regimen, these drugs are significantly more effective in treating HCV than previously available medications, have fewer side effects, require only 12-24 weeks of treatment for most patients, and do not require injected interferon in some patient groups. ${ }^{10-19}$ They are, however, costly-up to $\$ 168,000$ for a 24 -week course of SOF plus ribavirin. ${ }^{20}$

Although expensive, recent cost-effectiveness projections estimate the drugs to be a good value for some patient groups, since they may reduce future complications, health care costs, and improve quality of life. For example, Linas et al. (2015) found SOF regimens to be cost-effective in cirrhotic genotype 2 patients and in all genotype 3 patients. ${ }^{21}$ Rein et al. (2015) reported that SOF regimens were cost-effective in genotype $2 / 3$ and genotype $1 / 4$ patients, and SOF + SIM were cost-effective in genotype $1 / 4$ patients. ${ }^{22}$

Despite the effectiveness and value of the newer drugs, barriers to accessing treatment exist at several levels. Given the 3-6 million individuals with HCV in the United States and the high demand for these regimens, payers are concerned with having the resources for all who request treatment. With limited budgets, nearly all state Medicaid programs have implemented prior authorization (PA) requirements for accessing SOF and SIM to promote cost-effective use of resources. ${ }^{23}$ Some states have limited access in accordance with the American Association for the Study of Liver Diseases/Infectious Diseases Society of America (AASLD/IDSA) treatment guidelines, which, until recently, specified that individuals with advanced disease (e.g., advanced fibrosis, compensated cirrhosis, or organ transplant recipients) be given highest priority to these medications. ${ }^{24-26}$ Other states have implemented further restrictions that require individuals with SUD to be abstinent or in treatment. ${ }^{27,28}$ Barriers to care other than those imposed by PA restrictions also exist. For example, some potential patients may not have a regular source of care or may have difficulty adhering to treatment regimens because of medical or social conditions such as SUD or unstable housing. Physicians, too, may be reluctant to treat patients whom they perceive to be poor risks for achieving successful outcomes.

The Massachusetts Medicaid (MassHealth) program requires a PA to access HCV treatment, including SOF or SIM. Each request is reviewed by a pharmacist to ensure that the regimen requested meets the PA clinical requirements (see Appendix A, available in online article). Prescriber outreach is conducted for cases in which a more clinically appropriate regimen is available. Approval is furthered considered following PA resubmission for the optimized regimen. MassHealth does not deny requests based on disease severity, prescriber specialty, or presence of SUD. ${ }^{29}$ Since MassHealth has relatively few restrictions on these medications, the state offers an example of early SOF and SIM uptake among Medicaid members, as well as an opportunity to identify patient groups who are disproportionately more or less likely to have requested treatment for reasons other than those imposed by PA requirements. We evaluated the percentage of MassHealth members with HCV whose health care providers requested a PA for HCV treatment with SOF or SIM regimens, along with the percentage of these PA requests approved, and identified demographic, clinical, and provider-level characteristics associated with treatment request and approval.

\section{Methods}

\section{Data Source and Study Population}

We analyzed MassHealth Medicaid Management Information Systems enrollment and claims data linked to PA request data from members enrolled in the MassHealth Primary Care Clinician (PCC) plan, which is the MassHealth-administered managed care plan. The study period spanned from December 6, 2013-the first date after which SOF and SIM were approved by the FDA-through July 31, 2014. A cut-off date of July 31, 2014, was chosen to minimize the potential impact on prescribing patterns of the anticipated approval of additional new HCV medications in the last half of 2014

The study population consisted of MassHealth members who met the following criteria: (a) continuous enrollment in the PCC Plan for at least 1 year before the study end date, August 1, 2013-July 31, 2014; (b) 1 or more claims with an HCV diagnosis code (including International Classification of Diseases, Ninth Revision, Clinical Modification [ICD-9-CM] codes for chronic and unspecified HCV; Appendix B, available in online article) with a service date from 1 year before the study start date, December 6, 2012-July 31, 2014. Members who had documentation for insurance other than MassHealth noted in the medical claims at any time during the study period were excluded from the study population.

\section{Measures}

The main outcome of interest was the submission of a PA request by a member's health care provider (physician, nurse practitioner, or physician's assistant) for SOF and/or SIM any time between December 6, 2013, to July 31, 2014, obtained from the PA request database. The database also identified whether the request was ultimately approved or denied and the reason for denial. 
Demographic characteristics were obtained from MassHealth enrollment files. Variables included in the analysis were age ( $<30$ years, 30-49 years, 50-64 years), race/ethnicity (non-Hispanic white, non-Hispanic/black, Hispanic, and other), and gender. We further categorized the MassHealth PCC plan members by coverage type: MassHealth Standard, which provides the most comprehensive coverage and has the strictest income limits (133\% of federal poverty level for most individuals), and CommonHealth and Family Assistance, which have higher income limits but charge premiums and/ or copayments. All plans offered the same coverage for HCV medications.

Clinical characteristics were derived from claims data. Overall disease burden was measured with the Diagnostic Cost Group (DxCG) score, calculated for the MassHealth population. DxCG is a proprietary risk adjustment tool called DxCG Risk Solutions and was developed by Verisk Health. ${ }^{30}$ The DxCG score is calculated for every member every 6 months; a score of 1 represents the disease burden of the average MassHealth member, with scores greater than 1.0 indicating higher disease burden and scores less than 1.0 indicating lower burden than the average member. In addition, specific hepatic and nonhepatic-related diagnoses were identified by the presence of 1 or more claims with the relevant ICD-9-CM code in any position (Appendix B).

Hepatic decompensation was defined as ascites, spontaneous bacterial peritonitis, variceal hemorrhage, hepatic encephalopathy, or hepatic failure. Diagnoses of liver cirrhosis and liver transplant were also identified. Members with hepatic decompensation, liver cirrhosis, or liver transplant were further grouped into an "advanced disease" category. Recent treatment for HCV was defined as having 1 or more prescription fills for interferon or ribavirin at any time in the period from December 6, 2012, to December 6, 2013. Nonhepatic conditions included human immunodeficiency virus; SUDs including opioid use disorder; other drug-related or alcohol-related disorders; serious mental illness (SMI; schizophrenia and bipolar disorder); major and other depression; and other mental illness (anxiety, personality disorders, adjustment disorders, and other mental health diagnoses). Primary care site type was categorized as the outpatient clinic of an acute care hospital, group practice, hospital licensed health center, community health center, or individual physician practice.

Homeless status was determined by presence of ICD-9-CM code for homeless (Appendix B), or receipt of health care at a homeless shelter or through a homeless program at 1 of the 4 community health centers in Massachusetts that provide health care for the homeless.

\section{Analysis}

Descriptive characteristics of the sample are presented overall and for those who did and did not have a PA request for SOF or SIM. The percentage of the sample for whom treatment with SOF or SIM was requested, and the percentage of these requests that were approved are presented as well. Characteristics of members who did and did not have a PA request for SOF and/or SIM were compared with chi-square or Mann-Whitney tests, as appropriate. These tests were also used to compare the percentage of requests that were approved. Logistic regressions were fit to identify demographic and clinical predictors of PA request. We began our adjusted analysis with a logistic regression model including all demographic and clinical variables. We then fit a parsimonious model. Because there were no differences in the association between various substance use categories and PA request or between mental illness categories and PA request, we collapsed all SUDs into 1 category and all mental illness categories together. The race/ethnicity variable was also collapsed into white/non-Hispanic versus others because race/ethnicity groups other than white/Hispanic were similar with respect to PA request. Since very few members of the study population had CommonHealth or Family Assistance, coverage category was dichotomized as MassHealth Standard versus others.

We evaluated, in separate models, 2 interaction terms. The first evaluation indicated whether an individual had both a cooccurring mental illness and SUD, which was the case in 57\% of all members with mental illness, and the second evaluated whether the individual had both a SUD and advanced disease, which was the case in $73 \%$ of members with advanced liver disease. Neither of the terms was statistically significant, so neither was included in the final model. Because it is possible that recently treated members were successfully treated and did not currently have active HCV, we also ran a second model that excluded members who had been treated recently and who did not request treatment during the study period. All analyses were performed using SAS version 9.3 (SAS Institute, Cary, NC).

\section{Results}

Overall, there were 242,102 members with continuous enrollment and no third party insurance other than MassHealth during the study period. Of those members, 6,849 (2.8\%) had 1 or more claims with an HCV diagnosis. Table 1 presents the sample characteristics. The sample was 55\% male; $52 \%$ were aged 50-64 years; and nearly 60\% were white, non-Hispanic. Race/ethnicity was missing for almost $20 \%$ of the population. Approximately $62 \%$ had a diagnosis of chronic HCV, with $15 \%$ categorized as advanced disease. Mean DxCG score was 4.6, indicating high disease burden compared with the general MassHealth population. Sixty-nine percent had 1 or more SUD diagnoses, including $48 \%$ with a diagnosis of opioid-related 
TABLE 1 Demographic and Clinical Characteristics of MassHealth PCC Members with Hepatitis C Diagnosis, Overall and by PA Request Status, December 2013-July 2014

\begin{tabular}{|c|c|c|c|c|c|c|c|}
\hline \multirow[b]{2}{*}{ Independent Variables } & \multirow{2}{*}{\multicolumn{2}{|c|}{$\begin{array}{c}\text { Members with } \\
\text { Hepatitis C Diagnosis } \\
(\mathbf{n}=6,849)\end{array}$}} & \multicolumn{5}{|c|}{ PA Request Status } \\
\hline & & & \multicolumn{2}{|c|}{$\begin{array}{c}\text { No Request } \\
(\mathrm{n}=6,503 ; 94.9 \%)\end{array}$} & \multicolumn{2}{|c|}{$\begin{array}{c}\text { PA Request } \\
(\mathrm{n}=346 ; 5.1 \%)\end{array}$} & $P$ Value ${ }^{b}$ \\
\hline \multicolumn{8}{|l|}{ Demographic } \\
\hline Gender, n (\%) & & & & & & & 0.010 \\
\hline Female & 3,118 & $(45.5)$ & 2,985 & $(45.9)$ & 133 & $(38.4)$ & \\
\hline Male & 3,731 & $(54.5)$ & 3,518 & $(54.1)$ & 213 & $(61.6)$ & \\
\hline \multicolumn{8}{|l|}{ Age } \\
\hline Years, mean (SD) & 47.7 & $(11.8)$ & 47.5 & $(11.8)$ & 52.2 & $(9.05)$ & $<0.001^{\mathrm{c}}$ \\
\hline Category, years, n (\%) & & & & & & & $<0.001$ \\
\hline$<30$ & 611 & $(8.9)$ & 598 & $(9.2)$ & 13 & $(3.8)$ & \\
\hline $30-49$ & 2,708 & $(39.5)$ & 2,615 & $(40.2)$ & 93 & $(26.9)$ & \\
\hline $50-64$ & 3,530 & $(51.5)$ & 3,290 & $(50.6)$ & 240 & $(69.4)$ & \\
\hline \multicolumn{8}{|l|}{ Race, n (\%) } \\
\hline White & 3,955 & $(57.8)$ & 3,737 & $(57.5)$ & 218 & $(63.0)$ & 0.040 \\
\hline Black & 718 & $(10.5)$ & 692 & $(10.6)$ & 26 & $(7.5)$ & 0.060 \\
\hline Hispanic & 727 & $(10.6)$ & 693 & $(10.7)$ & 34 & $(9.8)$ & 0.630 \\
\hline Missing/unknown & 1,319 & $(19.3)$ & 1,259 & $(19.4)$ & 60 & $(17.3)$ & 0.350 \\
\hline MassHealth plan type, $\mathrm{n}(\%)$ & & & & & & & 0.010 \\
\hline Standard & 6,806 & $(99.4)$ & 6,465 & $(99.4)$ & 341 & $(98.6)$ & \\
\hline CommonHealth & 28 & $(0.4)$ & 23 & $(0.4)$ & & & \\
\hline Family Assistance & 15 & $(0.2)$ & 15 & $(0.2)$ & 0 & $(0.0)$ & \\
\hline Evidence of homelessness & 1,100 & $(16.1)$ & 1,069 & $(16.4)$ & 31 & $(9.0)$ & $<0.001$ \\
\hline \multicolumn{8}{|l|}{ Clinical } \\
\hline Recently received interferon and/or ribavirin, n (\%) & 216 & $(3.2)$ & 192 & $(3.0)$ & 24 & $(6.9)$ & $<0.001$ \\
\hline Chronic hepatitis C, $\mathrm{n}(\%)$ & 4,268 & $(62.3)$ & 3,952 & $(60.8)$ & 316 & $(91.3)$ & $<0.001$ \\
\hline Advanced disease, $\mathrm{n}(\%)$ & 1,056 & $(15.4)$ & 926 & $(14.2)$ & 130 & $(37.6)$ & $<0.001$ \\
\hline Hepatic decompensation & 663 & $(9.7)$ & 586 & $(9.0)$ & 77 & $(22.3)$ & $<0.001$ \\
\hline Liver cirrhosis & 721 & $(10.5)$ & 616 & $(9.5)$ & 105 & $(30.4)$ & $<0.001$ \\
\hline Liver transplant & 41 & $(0.6)$ & 30 & $(0.5)$ & 11 & $(3.2)$ & $<0.001$ \\
\hline HIV diagnosis & 925 & $(13.5)$ & 867 & $(13.3)$ & 58 & $(16.8)$ & 0.070 \\
\hline DxCG score, mean (SD) & 4.6 & $(3.7)$ & 4.6 & $(3.7)$ & 4.7 & $(3.3)$ & $0.040^{\mathrm{c}}$ \\
\hline Substance use disorder, n (\%) & 4,741 & $(69.2)$ & 4,537 & $(69.8)$ & 204 & $(59.0)$ & $<0.001$ \\
\hline Opioid & 3,254 & $(47.5)$ & 3,138 & $(48.3)$ & 116 & $(33.5)$ & $<0.001$ \\
\hline Other drug related & 3,270 & $(47.7)$ & 3,158 & $(48.6)$ & 112 & $(32.4)$ & $<0.001$ \\
\hline Alcohol & 1,878 & $(27.4)$ & 1,793 & $(27.6)$ & 85 & $(24.6)$ & 0.200 \\
\hline Tobacco & 3,340 & $(48.8)$ & 3,181 & $(48.9)$ & 159 & $(46.0)$ & 0.280 \\
\hline Comorbid advanced disease and SUD & 694 & $(11.2)$ & 694 & $(10.7)$ & 77 & $(22.3)$ & $<0.001$ \\
\hline Mental health diagnosis, n (\%) & 5,151 & $(75.2)$ & 4,887 & $(75.2)$ & 264 & $(76.3)$ & 0.630 \\
\hline Severe mental illness & 2,618 & $(38.2)$ & 2,497 & (38.4) & 121 & $(35.0)$ & 0.200 \\
\hline Depression (major and other) & 3,672 & $(53.0)$ & 3,431 & $(52.8$ & 196 & $(56.7)$ & 0.160 \\
\hline Other mental illness & 3,953 & $(57.8)$ & 3,761 & $(57.8)$ & 192 & $(55.5)$ & 0.390 \\
\hline Comorbid substance use disorder and mental illness & 3,927 & $(57.3)$ & 3,751 & $(57.7)$ & 176 & $(50.9)$ & 0.010 \\
\hline Disabled, n (\%) & 5,564 & $(81.2)$ & 5,256 & $(80.8)$ & 308 & $(89.0)$ & 0.001 \\
\hline Primary care site, $\mathbf{n}(\%)$ & & & & & & & $<0.003$ \\
\hline Individual physician & 241 & $(3.5)$ & 229 & $(3.5)$ & 12 & $(3.5)$ & \\
\hline Group practice organization & 3,123 & $(45.6)$ & 2,948 & $(45.3)$ & 175 & $(50.6)$ & \\
\hline Community health center & 2,625 & $(38.3)$ & 2,522 & $(38.8)$ & 103 & $(29.8)$ & \\
\hline Hospital licensed health center & 647 & $(9.5)$ & 613 & $(9.4)$ & 34 & $(9.8)$ & \\
\hline Outpatient department - acute & 213 & $(3.1)$ & 191 & $(2.9)$ & 22 & $(6.4)$ & \\
\hline \multicolumn{8}{|c|}{$\begin{array}{l}\text { ancludes MassHealth PCC members with 1+ claims with a diagnosis of hepatitis C in any position between December 1, 2012, and July 31, 2014, and who were conti } \\
\text { ously enrolled from December 6, 2013, to July 31, } 2014 \text {. } \\
\text { bChi-square test unless otherwise stated. } \\
\text { cWilcoxin-Mann-Whitney test. } \\
\text { dN }<11 \text {. } \\
\text { DxCG = Diagnostic Cost Group; HIV=human immunodeficiency virus; MassHealth= Massachusetts Medicaid; PA=prior authorization; PCC=Primary Care Clinicia } \\
\text { plan; SD=standard deviation; SUD = substance use disorder. }\end{array}$} \\
\hline
\end{tabular}


TABLE 2 Multivariable Model of Characteristics Associated with PA Requests Among MassHealth PCC Members with Hepatitis C Diagnosis, December 2013-July 2014

\begin{tabular}{|c|c|c|c|}
\hline \multirow[b]{2}{*}{ Characteristics $^{\mathrm{a}}$} & \multirow{2}{*}{$\begin{array}{l}\text { Odds } \\
\text { Ratio }^{\text {b }}\end{array}$} & \multicolumn{2}{|c|}{$\begin{array}{l}95 \% \text { Confidence } \\
\text { Limits }\end{array}$} \\
\hline & & Lower & Upper \\
\hline \multicolumn{4}{|l|}{ Demographic } \\
\hline \multicolumn{4}{|l|}{ Age (vs. <30) } \\
\hline $30-49$ & 1.36 & 0.74 & 2.52 \\
\hline $50-64$ & 2.00 & 1.07 & 3.73 \\
\hline \multicolumn{4}{|l|}{ Gender } \\
\hline Female & 0.81 & 0.64 & 1.03 \\
\hline \multicolumn{4}{|l|}{ MassHealth coverage type } \\
\hline Others vs. MassHealth Standard & 1.79 & 0.67 & 4.80 \\
\hline \multicolumn{4}{|l|}{ Race } \\
\hline White vs. others & 1.20 & 0.95 & 1.51 \\
\hline Disability & 1.15 & 0.77 & 1.72 \\
\hline Evidence of homelessness & 0.69 & 0.46 & 1.02 \\
\hline \multicolumn{4}{|l|}{ Clinical } \\
\hline HIV diagnosis & 1.28 & 0.93 & 1.74 \\
\hline DxCG score & 0.95 & 0.91 & 0.98 \\
\hline Recently received interferon and/or ribavirin & 1.64 & 1.03 & 2.61 \\
\hline Hepatic decompensation & 1.62 & 1.17 & 2.25 \\
\hline Liver cirrhosis & 3.04 & 2.24 & 4.11 \\
\hline Liver transplant & 3.00 & 1.38 & 6.52 \\
\hline Substance abuse (drug or alcohol) & 0.64 & 0.50 & 0.81 \\
\hline Mental illness & 1.43 & 1.08 & 1.89 \\
\hline \multicolumn{4}{|l|}{ Primary care site (vs. group practice ) } \\
\hline Community health center & 0.80 & 0.62 & 1.04 \\
\hline Hospital-licensed health center & 1.07 & 0.72 & 1.57 \\
\hline Individual physician & 0.85 & 0.46 & 1.57 \\
\hline Outpatient department-acute care hospital & 1.97 & 1.21 & 3.20 \\
\hline \multicolumn{4}{|c|}{$\begin{array}{l}\text { ancludes MassHealth PCC members with 1+ claims with a diagnosis of hepatitis C } \\
\text { in any position between December 1, 2012, and July 31, 2014, and who were con- } \\
\text { tinuously enrolled from August 1, 2013, to July 31, 2014. } \\
\text { bOutcome modeled is PA Request= "Yes." } \\
\text { DxCG = Diagnostic Cost Group; HIV=human immunodeficiency virus; } \\
\text { MassHealth= Massachusetts Medicaid; PA= prior authorization; PCC=Primary } \\
\text { Care Clinician plan. }\end{array}$} \\
\hline
\end{tabular}

SUD and $48 \%$ with a diagnosis for another drug-related SUD. Thirty-eight percent had a diagnosis of SMI; 53\% had a diagnosis of depressive disorder; and 58\% had a diagnosis for another mental illness. Fifty-seven percent had comorbid SUD and mental illness diagnoses. Over 80\% qualified for MassHealth because of disability.

Of the 6,849 members with HCV diagnosis, 346 (5.1\%) had a PA request for SOF or SIM submitted to MassHealth between December 6, 2013, and July 31, 2014, and the remaining 6,503 had either no PA request $(n=6,471)$ or a request for an HCV regimen that did not include SOF or SIM $(n=32)$. Of these requests, $41 \%$ were for SOF plus ribavirin; $30 \%$ were for SOF plus SIM; and 25\% were for SOF, ribavirin, and interferon, with 5\% for other regimens. A total of 37\% of PA requests came from an infectious disease specialist; $37 \%$ came from a gastroenterologist; $21 \%$ came from a hepatologist; and 4\% came from an internal/family medicine practitioner. Table 1 presents demographic and clinical characteristics of members by PA request status. Compared with members who did not have a PA request for SOF or SIM, those with a request were older; more likely to be a white male; and more likely to have a MassHealth standard plan and qualify for MassHealth through presence of a disability, have evidence of advanced disease, and have been treated recently. Diagnosis of opioid- or other drug-related SUD, homelessness, and receipt of primary care at a community health center were less frequent among members with a PA request for SOF or SIM relative to those without. Ninety percent of PA requests were approved. Of the PA requests not approved, the most frequent reason was incomplete information received from the health care provider (e.g., lack of documented previous treatment history or contraindication to peginterferon alfa, if applicable). Following the denials, prescriber offices were contacted to inform them of the documentation required for further consideration. Among members with a PA request, those with a diagnosis of opioid abuse were slightly more likely to ultimately have an approval ( $95 \%$ vs. $89 \%, P=0.04$ ) than members without the diagnosis. Other characteristics were similar between members whose PAs for SOF and/or SIM were approved or denied.

Table 2 presents the final regression model results. In adjusted analyses, members with liver cirrhosis and history of liver transplant each had 3 times the odds of having a PA request compared with those without these diagnoses. Other positive predictors of having a PA request included being aged 50-64 years, having lower DxCG scores, and having a history or presence of hepatic decompensation. Compared with members who received primary care in a group practice, those who received care in an outpatient department of an acute care hospital had twice the odds of having a PA request, while members with an alcohol or drug use diagnosis had nearly $40 \%$ lower odds of having a submitted PA request, compared with those without an SUD. The sensitivity analysis excluding members who had been recently treated and without a PA request yielded nearly identical results (data not shown).

\section{Discussion}

While there have been reports of state Medicaid spending for new HCV drugs, ${ }^{31}$ to our knowledge this study is the first population-based analysis of the percentage and characteristics of Medicaid members requesting treatment with SOF- or SIMbased regimens during the first 8 months of their availability. Our findings indicate that in the MassHealth PCC plan, which does not limit coverage based on liver fibrosis stage, prescriber specialty, or presence of a SUD, only a small percentage of 
members with HCV infection had a PA request for SOF- and/or SIM-based regimens submitted by their health care providers. Given the limited PA restrictions in Massachusetts, this low number likely reflects patient-level barriers to care and provider decision.

We found several patient-level characteristics associated with PA requests, identifying patient groups who, to date, may have encountered barriers to receiving treatment with these new medications. Most notably, after adjusting for demographic and clinical characteristics, members with SUD had only approximately two thirds the odds of having a PA request for SOF- or SIM-based regimens submitted, compared with members with no SUD. Research suggests that even if insured, individuals with SUD have low levels of preventive care. ${ }^{32}$ These members may therefore have been less likely than others to have had a discussion with their PCPs during the study period that resulted either in a PA request from the PCP or a referral for assessment for treatment by a specialist. It is also possible that health care providers were more reluctant to prescribe treatment to individuals with SUD because of concerns of adherence or reinfection. While it has been documented that individuals with SUD have decreased adherence to longterm medication regimens such as antiretroviral therapy, ${ }^{33,34}$ there is no clear evidence that active drug users have lower adherence to $\mathrm{HCV}$ treatment regimens, poorer outcomes, or higher risk of reinfection compared with other HCV patients in the era of interferon-containing regimens. ${ }^{35,36}$ Whether this holds in the all-oral HCV regimens is not yet known and will be the subject of future analyses in this population.

Although medication adherence is a perennial concern among individuals with psychiatric disorders, having a mental illness, severe or otherwise, was not a barrier to SOF or SIM treatment referral. ${ }^{37,38}$ This finding challenges the assumption that the lower rate of treatment referral associated with SUD is entirely because of concerns about adherence. Further study is needed to better understand how and why these comorbid conditions influence decisions about HCV treatment.

We found that members with more advanced liver disease were more likely to have had a PA request for SOF or SIM submitted, suggesting that health care providers may be following AASLD/IDSA guidelines for prioritizing treatment for those with advanced liver disease, despite this not being an explicit requirement for reimbursement in the MassHealth PCC plan. Patients with more advanced liver disease may also have been more likely to receive medical care during the study period so may have had an opportunity to discuss new options for treatment, as well as have more urgent need for treatment. Despite a higher number of PA requests for SOF or SIM among members with advanced disease, only $12 \%$ of this subgroup had a PA request. This suggests that there remains a large pool of patients who may benefit most from treatment with these agents that were not referred for treatment in the first months of their availability. More work may need to be done to facilitate outreach to these high-need patients.

With the arrival of SOF and SIM came projections that large numbers of individuals with state-funded insurance could potentially receive these medications (e.g., 11,000 in Massachusetts alone). ${ }^{39}$ Our results demonstrate that, to date, the number of patients for whom treatment was requested has been far smaller than predicted. If the HCV prevalence and treatment patterns are the same for all Massachusetts residents with state-funded insurance as those participating in the Medicaid-administered managed care plan, the estimate of the number treated during the first year after approval would be closer to 1,400 (PCC members represent $27 \%$ of total MassHealth population ${ }^{40}$ ). While comparable data from other states are not available, it is likely that the percentage of eligible members who are treated is similar or lower given the more restrictive requirements in many other states. These findings suggest, therefore, that there is still a large pool of untreated patients who may benefit from new treatments and who may request treatment in future years.

Our results represent treatment referrals only during the first few months of the new HCV medications' availability. New treatments often take time to diffuse within the health care system, although these medications were highly anticipated among practitioners who treat HCV. Treatment seeking and referral rates may rise as more patients are diagnosed, and provider and patient experience with direct acting HCV medications grows. Moreover, the introduction of ledipasvir and SOF combination therapy (SOF/LED; Harvoni) and ombitasvir, paritaprevir, and ritonavir plus dasabuvir (PTV/r/OBV+DSV; Viekira Pak) in late 2014 will again alter treatment patterns for HCV infection in Medicaid and other patient populations. These all-oral treatment regimens, primarily indicated for the genotype 1 disease, offer improved efficacy and patient tolerance, reduced regimen complexity, and shorter courses of therapy in some patients. ${ }^{41,42}$ It is possible that the low number of PA requests reflects in part physicians delaying treatment for genotype 1 patients, who represent $75 \%$ of all chronic HCV patients and are not identifiable in claims data, ${ }^{43}$ in anticipation of FDA approval of these all-oral regimens. However, the all-oral combination of SOF+RBV, which was standard of care for genotypes 2 and 3 infection until daclatasvir was approved for genotype 3 infection in August 2015, was only used for a fraction of the anticipated $25 \%$ of patients with these genotypes. While future analyses will need to be conducted to identify characteristics associated with SOF/LED and PTV/r/ $\mathrm{OBV}+\mathrm{DSV}$, it is expected that the profile of patients who have requests for these medications will be similar to the profile of patients presented in these analyses. 


\section{Limitations}

Our analyses are subject to several limitations. Since claims data are collected for billing and not research purposes, recording of ICD-9-CM codes for HCV may not be complete, particularly if health care visits during the study period were unrelated to HCV. Of additional concern is that it is not possible to ascertain whether the presence of an ICD-9-CM code for HCV indicates active disease or history of HCV that has been treated successfully before the study period. Our estimate of $2.8 \%$ prevalence of $\mathrm{HCV}$, however, is similar to a National Health and Nutrition Examination Survey estimate of 2.6\% of U.S. residents living below the poverty line. ${ }^{3}$ Nevertheless, we may still be over- or underestimating the number of members with active, diagnosed disease in our population. Furthermore, if misreporting is differential with respect to submission of a PA request or any demographic or clinical characteristics, our estimates of the percentage requesting treatment may be misestimated and the odds ratios for predictors of PA requests may be biased. For example, if members without documentation of hepatic decompensation are less likely to have active disease, we may be overestimating the association between hepatic decompensation and PA request. Although we were unable to identify treatment before December 2012 in the dataset, it was reassuring that a sensitivity analysis excluding members with treatment from December 2012 to December 2013with the assumption that these members did not have active disease-did not change the study results. Reliance on ICD9-CM codes for diagnosis of comorbid conditions is subject to similar limitations. Finally, claims do not provide detailed clinical information. In our analysis, the HCV genotype is an important clinical predictor of PA requests that are not available in our dataset.

\section{Conclusions}

Our data provide a look at early treatment patterns after the introduction of highly effective, although expensive, HCV medications in Massachusetts' Medicaid program-a program with very few restrictions on treatment access. Our findings suggest that uptake of these direct-acting medications was not as rapid as predicted. However, treatment referral was not uniform. Most notably, individuals with SUD, who comprise a large portion of individuals with $\mathrm{HCV}$, were less likely to have treatment requested than other members. Whether these patterns will continue as patients and providers gain more experience with the new medications for $\mathrm{HCV}$, and as more medications become available, remains to be seen. In order to reduce future health care costs and premature mortality associated with $\mathrm{HCV}$, the number of patients receiving these potentially curative antiviral treatments must be increased. This study suggests that there are barriers to treatment access in addition to the high cost of these medications that will have to be addressed in order to achieve this goal.

\section{Authors}

KAREN M. CLEMENTS, ScD, MPH; PARAG KUNTE, MPH; and ELIZABETH O'CONNELL, MS, Center for Health Policy and Research, University of Massachusetts Medical School, Shrewsbury. ROBIN E. CLARK, PhD, Department of Family Medicine and Community Health, and PAVEL LAVITAS, PharmD, BCPS, Clinical Pharmacy Services, University of Massachusetts Medical School, Shrewsbury. CAMILLA S. GRAHAM, MD, MPH, Division of Infectious Diseases, Beth Israel Deaconess Medical Center, Boston, Massachusetts. KIMBERLY LENZ, PharmD, Office of Clinical Affairs, and PAUL JEFFREY, PharmD, Office of Clinical Affairs, University of Massachusetts Medical School, Shrewsbury.

AUTHOR CORRESPONDENCE: Karen M. Clements, ScD, MPH, Center for Health Policy and Research, University of Massachusetts Medical School, 333 S. St., Shrewsbury MA 01545.

Tel.: 508.856.3193; Fax: 508.856.8543;

E-mail: Karen.clements@umassmed.edu.

\section{DISCLOSURES}

No outside funding supported this research. Internal funding was provided by the Commonwealth of Massachusetts. Lavitas has received compensation from University of Tennessee Advanced Studies in Medicine for development of CPE activity. Graham has consulted for the National Viral Hepatitis Roundtable and the Department of Health and Human Services, has received payment from Medscape for CME development, and is employed by Trek Therapeutics. Jeffrey has received payment for guest lectures at Boston University and Harvard University.

Study concept and design were primarily contributed by Clark and Clements, along with Graham, Lenz, and Jeffrey. Kunte collected the data, which were interpreted by Graham, Lenz, and Jeffrey, with assistance from Lavitas, Clark, and Clements. The manuscript was written primarily by Clements, along with O'Connell and assisted by Graham, and revised by all the authors.

\section{REFERENCES}

1. Armstrong GL, Wasley A, Simard EP, McQuillan GM, Kuhnert WL, Alter MJ. The prevalence of hepatitis $C$ virus infection in the United States, 1999 through 2002. Ann Intern Med. 2006;144(10):705-14. Available at: http://annals.org/article. aspx?articleid=723191. Accessed March 22, 2016.

2. Chak E, Talal AH, Sherman KE, Schiff ER, Saab S. Hepatitis C virus infection in USA: an estimate of true prevalence. Liver Int. 2011;31(8):1090-101. Available at: http://onlinelibrary.wiley.com/doi/10.1111/j.1478-3231.2011. 02494.x/epdf. Accessed March 22, 2016.

3. Denniston MM, Jiles RB, Drobeniuc J, et al. Chronic hepatitis C virus infection in the United States, National Health and Nutrition Examination Survey 2003 to 2010. Ann Intern Med. 2014;160(5):293-300. Available at: http://www.ncbi.nlm.nih.gov/pmc/articles/PMC4562398/. Accessed March 22, 2016

4. van der Meer AJ, Veldt BJ, Feld JJ, et al. Association between sustained virological response and all-cause mortality among patients with chronic hepatitis C and advanced hepatic fibrosis. JAMA. 2012;308(24):2584-93. Available at: http://jama.jamanetwork.com/article.aspx?articleid=1487498. Accessed March 22, 2016.

5. Yee HS, Chang MF, Pocha C, et al. Update on the management and treatment of hepatitis $C$ virus infection: recommendations from the Department of Veterans Affairs Hepatitis C Resource Center Program and the National Hepatitis C Program Office. Am J Gastroenterol. 2012;107(5):669-89. 
6. Shepherd J, Brodin H, Cave C, Waugh N, Price A, Gabbay J. Pegylated interferon alpha-2a and-2b in combination with ribavirin in the treatment of chronic hepatitis C: a systematic review and economic evaluation. Health Technol Assess. 2004;8(39):iii-iv, 1-125. Available at: http://www.ncbi.nlm. nih.gov/pubmedhealth/PMH0015094/. Accessed March 22, 2016.

7. Park C, Jiang S, Lawson K. Efficacy and safety of telaprevir and boceprevir in patients with hepatitis $C$ genotype 1: a meta-analysis. J Clin Pharm Ther. 2014;39(1):14-24

8. U.S. Food and Drug Administration. FDA approves Sovaldi for chronic hepatitis C. December 2013, updated October 2014. Available at: http:// www.fda.gov/newsevents/newsroom/pressannouncements/ucm377888.htm. Accessed March 22, 2016.

9. U.S. Food and Drug Administration. Olysio (simeprevir) for the treatment of chronic hepatitis C in combination antiviral treatment. November 22, 2013, updated September 2014. Available at: http://www.fda.gov/forpatients/illness/hepatitisbc/ucm377234.htm. Accessed March 22, 2016.

10. Jacobson IM, Dore GJ, Foster GR, et al. Simeprevir with pegylated interferon alfa 2 a plus ribavirin in treatment-naïve patients with chronic hepatitis C virus genotype 1 infection (QUEST-1): a phase 3, randomised, doubleblind, placebo-controlled trial. Lancet. 2014;384(9941):403-13.

11. Manns M, Marcellin P, Poordad F, et al. Simeprevir with pegylated interferon alfa $2 \mathrm{a}$ or $2 \mathrm{~b}$ plus ribavirin in treatment-naive patients with chronic hepatitis $C$ virus genotype 1 infection (QUEST-2): a randomized, doubleblind, placebo-controlled phase 3 trial. Lancet. 2014;384(9941):414-26.

12. Forns X, Lawitz E, Zeuzern S, et al. Simeprevir with peginterferon and ribavirin leads to high rates of SVR in patients with HCV genotype 1 who relapsed after previous therapy: a phase 3 trial. Gastroenterol. 2014;146:1669-79.

13. Hayashi N, Izumi N, Kumada H, et al. Simeprevir with peginterferon/ ribavirin for treatment-naive hepatitis $C$ genotype 1 patients in Japan: CONCERTO-1, a phase III trial. J Hepatol. 2014;61(2):219-27.

14. Izumi N, Hayashi N, Kumada H, et al. Once-daily simeprevir with peginterferon and ribavirin for treatmentexperienced $\mathrm{HCV}$ genotype l-infected patients in Japan: the CONCERTO-2 and CONCERTO-3 studies. J Gastroenterol. 2014;49(5):941-53. Available at: http://link.springer.com/artic le/10.1007\%2Fs00535-014-0949-8. Accessed March 22, 2016.

15. Kumada H, Hayashi N, Izumi N, et al. Simeprevir (TMC435) once daily with peginterferon $a-2 b$ and ribavirin in patients with genotype-1 hepatitis- $C$. Hepatol Res. 2015;45(5):501-13.

16. Lawitz E, Mangia A, Wyles D, et al. Sofosbuvir for previously untreated chronic hepatitis C infection. N Engl J Med. 2013;368(20):1878-87. Available at: http://www.nejm.org/doi/full/10.1056/NEJMoal214853. Accessed March 22, 2016.

17. Jacobson IM, Gordon SC, Kowdley KV, et al. Sofosbuvir for hepatitis C genotype 2 or 3 in patients without treatment options. New Engl J Med. 2013;368(20):1867-77. Available at: http://www.nejm.org/doi/full/10.1056/ NEJMoal214854. Accessed March 22, 2016.

18. Zeuzem S, Dusheiko GM, Salupere R, et al. Sofosbuvir and ribavirin for genotypes 2 and 3. N Engl J Med. 2014;370(21):1993-2001. Available at: http:// www.nejm.org/doi/full/10.1056/NEJMoal316145. Accessed March 22, 2016.

19. Sulkowski MS, Naggie S, Lalezari J, et al. Sofosbuvir and ribavirin for hepatitis C in patients with HIV coinfection. JAMA. 2014;312(4):353-61. Available at: http://jama.jamanetwork.com/article.aspx?articleid=1889138. Accessed March 22, 2016

20. Brennan T, Shrank W. New expensive treatments for hepatitis C infection. JAMA. 2014;312(6):593-94.

21. Linas BP, Barter DM, Morgan JR, et al. The cost-effectiveness of sofosbuvir-based regimens for treatment of hepatitis $C$ virus genotype 2 or 3 infection. Ann Intern Med. 2015;162(9):619-29.

22. Rein DB, Wittenborn JS, Smith BD, Liffmann DK, Ward JW. The costeffectiveness, health benefits, and financial costs of new antiviral treatments for hepatitis C virus. Clin Infect Dis. 2015;61(2):157-68. Available at: http:// cid.oxfordjournals.org/content/61/2/157.long. Accessed March 22, 2016.
23. Barua S, Greenwald R, Grebely J, Dore GJ, Swan T, Taylor LE. Restrictions for Medicaid reimbursement of sofosbuvir for the treatment of hepatitis $C$ virus infection in the United States. Ann Intern Med. 2015;163(3):215-23. Available at: http://annals.org/article.aspx?articleid= 2362306. Accessed March 22, 2016

24. California Department of Health Care Services. Utilization and treatment policy for simeprevir and sofosbuvir in the management of hepatitis $\mathrm{C}$. June 30, 2014. Available at: http://www.dhcs.ca.gov/Documents/Hep_C_ Policy.pdf. Accessed March 22, 2016.

25. Oregon Health Authority. Oregon Medicaid pharmaceutical services: prior authorization criteria. October 14, 2014. Available at: http://www.oregon.gov/oha/healthplan/tools/Oregon\%20Medicaid\%20PA\%20Criteria,\%20 October\%202014.pdf. Accessed March 22, 2016.

26. American Association for the Study of Liver Diseases (AASLD), Infectious Diseases Society of America (IDSA). HCV guidance: recommendations for testing, managing, and treating hepatitis C. 2015, updated February 24, 2016. Available at: http://www.hcvguidelines.org/full-reportview. Accessed March 22, 2016.

27. Pennsylvania Department of Human Services. Requirements for prior authorization of hepatitis C agents. December 9, 2014. Available at: http://www.dhs.state.pa.us/cs/groups/webcontent/documents/bulletin_ admin/c_132846.pdf. Accessed March 22, 2016.

28. Illinois Department of Healthcare and Family Services. General criteria for prior approval of newer direct-acting antivirals (DAA) for hepatitis C. 2015. Available at: http://www.illinois.gov/hfs/SiteCollectionDocuments/ HepatitisC_General_Criteria.pdf. Accessed March 22, 2016.

29. Massachusetts Health and Human Services. Therapeutic class tables. Table 44: Hepatitis antiviral agents. April 2004, updated March 3, 2016. Available at: https://masshealthdruglist.ehs.state.ma.us/MHDL/pubtheradetail.do?id=52\&drugId=4600. Accessed March 22, 2016.

30. Ash AS, Ellis RP, Pope GC, et al. Using diagnoses to describe populations and predict costs. Health Care Financ Rev. 2000;21(3):7-28. Available at: http://www.ncbi.nlm.nih.gov/pmc/articles/PMC4194673/. Accessed March 22, 2016.

31. Walker J. Gilead's $\$ 1,000$ pill is hard for states to swallow. The Wall Street Journal. Available at: http://www.wsj.com/articles/gileads-1-000-hep-c-pillis-hard-for-states-to-swallow-1428525426. Accessed March 22, 2016.

32. Benjamin-Johnson R, Moore A, Gilmore J, Watkins K. Access to medical care, use of preventive services, and chronic conditions among adults in substance abuse treatment. Psychiatr Serv. 2009;60(12):1676-79.

33. Azar MM, Springer SA, Meyer JP, Altice FL. A systematic review of the impact of alcohol use disorders on HIV treatment outcomes, adherence to antiretroviral therapy and health care utilization. Drug Alcohol Depend. 2010;112(3):178-93. Available at: http://www.ncbi.nlm.nih.gov/pmc/articles/ PMC2997193/. Accessed March 22, 2016.

34. Malta M, Strathdee SA, Magnanini MMF, Bastos FI. Adherence to antiretroviral therapy for human immunodeficiency virus/acquired immune deficiency syndrome among drug users: a systematic review. Addiction. 2008;103(8):1242-57.

35. Aspinall EJ, Corson S, Doyle JS, et al. Treatment of hepatitis C virus infection among people who are actively injecting drugs: a systematic review and meta-analysis. Clin Infect Dis. 2013;57(Suppl 2):S80-89. Available at: http://cid.oxfordjournals.org/content/57/suppl_2/S80.long. Accessed March 22, 2016.

36. Higgs P, Sacks-Davis R, Gold J, Hellard M. Barriers to receiving hepatitis $C$ treatment for people who inject drugs: myths and evidence. Hepat Mon. 2011;11(7):513-18. Available at: http://www.ncbi.nlm.nih.gov/pmc/articles/ PMC3212767/. Accessed March 22, 2016.

37. Robinson D. First-episode schizophrenia. CNS Spectr. 2010;15(Suppl 6):4-7. 38. Kane JM. Treatment adherence and long-term outcomes. CNS Spectr. 2007;12(10 Suppl 17):21-26. 
39. Miller $S$. State governments may spend $\$ 55$ billion on hepatitis $C$ medications. Express Scripts. July 17, 2014. Available at: http://lab.expressscripts.com/insights/specialty-medications/state-governments-may-spend\$55-billion-on-hepatitis-c-medications. Accessed March 22, 2016.

40. University of Massachusetts Medical School, Center for Health Law and Economics. MassHealth: the basics. Facts, trends, and national context. April 2014. Available at: http://bluecrossmafoundation.org/publication/ updated-masshealth-basics-facts-trends-and-national-context. Accessed March 22, 2016.

41. Harvoni (ledipasvir and sofosbuvir) tablets, for oral use. Gilead Sciences. 2014, updated February 20, 2016. Available at: https://www.gilead.com/ / media/Files/pdfs/medicines/liver-disease/harvoni/harvoni_pi.pdf. Accessed March 22, 2016.
42. Viekira Pak (ombitasvir, paritaprevir, and ritonavir tablets; dasabuvir tablets), co-packaged for oral use. AbbVie. 2014, updated December 2014. Available at: http://www.accessdata.fda.gov/drugsatfda_docs/ label/2014/206619lbl.pdf. Accessed March 22, 2016.

43. Nainan OV, Alter MJ, Kruszon-Moran D, et al. Hepatitis C virus genotypes and viral concentrations in participants of a general population survey in the United States. Gastroenterology. 2006;131(2):478-84. Available at: http://www.gastrojournal.org/article/S0016-5085(06)01236-4/fulltext. Accessed March 22, 2016. 


\section{APPENDIX A MassHealth Prior Authorization Requirements for Sofosbuvir and Simeprevir}

Sofosbuvir

- Documentation of the following is required:

o For HCV genotype 1 and 4

- diagnosis of chronic hepatitis $C$; and

- hepatitis C genotype 1 or 4 ; and

- member is $\geq 18$ years of age; and

- requested dose is $400 \mathrm{mg}$ once daily; and

- requested duration of therapy (i.e., number of weeks); and

- member is receiving pegylated interferon and ribavirin.

o For HCV genotype 2 and 3

- diagnosis of chronic hepatitis $C$; and

- hepatitis C genotype 2 or 3 ; and

- member is $\geq 18$ years of age; and

- requested dose is $400 \mathrm{mg}$ once daily; and

- requested duration of therapy (i.e., number of weeks); and

- member is receiving ribavirin.

o For pre-liver transplant in hepatocellular carcinoma (HCC)

- diagnosis of chronic hepatitis $C$; and

- hepatitis C genotype $1,2,3$, or 4; and

- diagnosis of HCC and member is awaiting a liver transplant; and

- member is $\geq 18$ years of age; and

- requested dose is $400 \mathrm{mg}$ once daily; and

- requested duration of therapy (i.e., number of weeks); and

- member is receiving ribavirin.

Simeprevir

- Documentation of the following is required:

o diagnosis of chronic hepatitis C; and

o hepatitis $C$ genotype 1 ; and

o for requests for members with genotype la only, documentation of absence of NS3 Q80K polymorphism; and

o member is $\geq 18$ years of age; and

o member is not coinfected with hepatitis B; and

o member is receiving pegylated interferon and ribavirin; and

o requested duration of therapy (i.e., number of weeks); and

o member has not been previously treated with a regimen containing an HCV protease inhibitor; and

o requested dose is $150 \mathrm{mg}$ once daily; or

o one of the following:

- documentation that this is the initiation of therapy; or

- HCV RNA lab values supporting continued use. 
APPENDIX B Codes Used for Population Identification

\begin{tabular}{l|l}
\hline Diagnosis & \multicolumn{1}{c}{ Codes } \\
\hline Any hepatitis C & ICD-9-CM: 070.41, 070.44, 070.51, 070.54, 070.70, 070.71, V02.62 \\
\hline Chronic hepatitis C & ICD-9-CM: 070.44, 070.54 \\
\hline HIV & ICD-9-CM: 042, V08 \\
\hline Liver transplant & $\begin{array}{l}\text { ICD-9-CM: V42.7, 996.82 } \\
\text { ICD-9-CM Procedure: 505 } \\
\text { CPT: 47133, 47135, 47136, 47143, 47144, 47145, 47146, 47147 }\end{array}$ \\
\hline Hepatic decomposition & $\begin{array}{l}\text { ICD-9-CM: 070.41, 070.44, 070.49, 070.6, 155.0, 456.0, 456.1, 456.2x, 567.0, 567.2x, 567.8x, 567.9, 570, 572.2, } \\
\text { 572.3, 572.4, 572.8, 789.5x }\end{array}$ \\
\hline Liver cirrhosis & ICD-9-CM: 571.2, 571.5 \\
\hline Severe mental illness & ICD-9-CM: 296.4, 296.5, 296.6, 296.7, 296.8x, 294.0, 294.8, 294.9, 295.x, 296.9x, 297.x, 298.x, 299.8, 299.9 \\
\hline Major and other depression & ICD-9-CM: 296.2, 296.3, 300.4, 311 \\
\hline Other mental illness & ICD-9-CM: 294.1, 296.0, 296.1, 300.0x, 300.1x, 300.2x, 300.3, 300.5, 300.6, 300.7, 300.8x, 300.9, 301.x, 302.x, \\
\hline Substance abuse alcohol & I06.x, 307.x, 308.x, 309.0, 309.1, 309.2x, 309.3, 309.4, 309.8x, 309.9, 312.xx, 313.xx, 314.xx, 316 \\
\hline Substance abuse opioid & ICD-9-CM: 291.xx, 303.x, 305.0, 535.3, 571.0, 571.1, 571.2, 571.3 \\
\hline Substance abuse other drugs & ICD-9-CM: 304.0 \\
\hline Substance abuse tobacco & ICD-9-CM: 292.xx, 304.1, 304.2, 304.3, 304.4, 304.5, 304.6, 304.7, 304.8, 304.9, 305.2, 305.3, 305.4, 305.5, 305.6, \\
\hline Homelessness & ICD-9-CM: 305.1 \\
\hline
\end{tabular}

CPT = Current Procedural Terminology; HCPCS = Healthcare Common Procedure Coding System; HIV=human immunodeficiency virus; ICD-9-CM = International Classification of Diseases, Ninth Revision, Clinical Modification. 